\title{
Political events and public views on climate change
}

\section{Thomas Dietz ${ }^{1,2}$}

Published online: 29 July 2020

(C) Springer Nature B.V. 2020

The gap between the scientific assessment of climate risks and the actions being taken to mitigate and adapt to climate change is stunning. Why does this gap exist, and what can be done to close it? First, it is important to remember that facts are never sufficient for making decisions (Dietz 2013). Decisions require weighing costs, benefits, and risks, distributed differentially across the globe. Making tradeoffs involves values. So value differences and value conflicts have to be resolved in order to take action. Second, policy to respond to climate inevitably involves many interested and affected parties and multiple issues. That complexity alone can slow processes even when there is consensus about facts and values. But the active denial of the scientific consensus by some members of the public and some elites is a particularly troubling obstacle to climate action (McCright and Dunlap 2010; McCright et al. 2016). Hahnel et al. (2020) and Zawadzki et al. (2020) offer important insights into climate denial. They use a major political event in the USA, the election of Republican President Donald Trump, as a natural experiment to reveal some of the dynamics of climate denial and climate action.

Politics is both a top-down and a bottom-up process (McLaughlin 2012; McLaughlin and Dietz 2008). The actions of citizens influence elites and policy. But the public is in turn influenced by larger forces and powerful actors, including politicians. The Republican victory in the 2016 election gives an opportunity to see how a large-scale political change impacted public opinion, thus linking the micro level of public views with the macro level of elites and national events. Most research tends to work at one level or the other. But crossing levels of analysis is essential if we are to understand the interplay of power structures and individual views and actions.

The ideological split in views on climate change has been much studied. Conservatives (Republicans in the USA) are much more likely to be deniers of the scientific consensus than liberals (Democrats) (McCright et al. 2016). That is, conservatives are less likely to believe that the climate is changing, that the causes are largely anthropogenic, that the risks are substantial, and that action needs to be taken. The ideological difference about climate has

Thomas Dietz

tdietzvt@gmail.com

1 Department of Sociology, Environmental Science and Policy Program and Center for Systems Integration and Sustainability, Michigan State University, East Lansing, MI, USA

2 Gund Institute for Environment, University of Vermont, Burlington, VT, USA 
grown more substantial over time. Over the last decade, while Democrats, Independents, and even liberal to moderate Republicans have increasingly accepted that global warming is happening and that it is worrisome, conservative Republicans have become less likely to see climate change as real and a cause for worry (Ballew et al. 2019). This phenomenon is strongest in the USA and stronger in Anglophone countries in general (Hornsey et al. 2018). The ideological split on climate change was foreshadowed as much as 50 years ago. Earth Day in 1970 mobilized perhaps 14,000 events at colleges, universities, and communities and was one of the largest social movement actions in US history (Dietz 2020). It appears that Earth Day increased environmental concern among liberals and moderates, but it had no impact on conservatives (Johnson and Schwadel 2019).

Most members of the public do not come to their views on climate change through a careful reading of the scientific literature. Humans routinely use a variety of cognitive shortcuts to make decisions quickly and efficiently. This is sometimes referred to as System I thinking, in contrast to System II thinking that deploys careful weighing of evidence, costs, benefits, and risks, essentially the "rational actor model" (Kahneman 2011). In System I, we consider the sources of new information, and are more likely to accept information from sources we perceive as similar to us. We are more likely to accept new information if it is congruent with our existing views. When presented with facts, we may think about the implications of those facts for policy and reject facts that might lead to policies we do not like. So our values, our existing beliefs, and our social networks substantially shape how our beliefs evolve. In turn, as we form social networks from which we derive information, we tend to link to people who think the way we do and strongly avoid those who think differently (Henry and Vollan 2014; Jasny et al. 2018).

An extensive research literature examining these processes spans the social sciences. Unfortunately, a number of different terms have emerged to label what are roughly the same phenomena. In particular, the process by which we let our assessment of facts be influenced by values, prior beliefs, policy preferences, and by how we feel about a source of information is variously called biased assimilation, hot cognition, or motivated reasoning. Ongoing research offers some subtle distinctions across these concepts (Bolsen and Palm 2019; Druckman and McGrath 2019). Here, I will use the oldest of the terms, biased assimilation, to describe the general phenomena.

We are all susceptible to these "heuristics and biases." In most day-to-day situations, these shortcuts work well and save a great deal of time and cognitive effort. Indeed, the ability to learn from others, the basis of biased assimilation, seems to be at the heart of human ecology and cultural evolution (Henrich 2015). We also have mechanisms to overcome the biases. We use the scientific method specifically to counteract these tendencies in assessing new information (Elliott 2017). Indeed, some disciplines deploy double, rather than single, blind peer review to ensure that the prestige of authors or other author characteristics does not bias assessment of the quality of a paper.

Unfortunately, these shortcuts can be manipulated by those who want to shape our thinking (Cialdini 2007 [1984]). Climate denial is a case in point-public views have been influenced by ongoing campaigns to discredit the scientific consensus and block action, exploiting our cognitive shortcuts (Givens et al. 2020; McCright 2016; McCright et al. 2016). The history of such campaigns stretches back at least to arguments about the introduction of tetraethyl lead as a gasoline additive, and have been mounted around acid precipitation, ozone depletion, and most recently the COVID-19 pandemic (Michaels 2020). 
Because of biased assimilation, the views of prominent people, such as Presidential candidates, can have a substantial influence on public opinion. Research on the bases for support for and opposition to Trump's candidacy is ongoing, but it appears that immigration and racial issues were important (Algara and Hale 2019; Hooghe and Dassonneville 2018; Setzler and Yanus 2018; Wright and Esses 2019). Members of the public who aligned with him on these or any of a variety of other issues, or supported him simply because they identify as Republicans, could then be expected to also align with his views on climate change. While environmental issues were not central in the 2016 Presidential campaign, Trump clearly signaled his skepticism about action on climate policy, support for the coal industry, and opposition to environmental regulation (Bomberg 2017; Rosenbaum 2020). How then did Trump's election influence public views on climate change? Hahnel et al. and Zawadzki et al. offer important insights on the impact of Trump's presidency by considering the social psychological processes that shape public views.

\section{Impacts of the election and early administration}

Hahnel et al. conducted a panel study, re-interviewing the same respondents roughly 1 month before and 2 weeks after the election. Post-election, both Republicans and Democrats held more positive feelings toward the Republican Party than they had before the election, although the effect was much stronger for Republicans than for Democrats. Republicans perhaps felt vindicated while, as the authors note, Democrats may have been reducing cognitive dissonance. Certainly, many political commentators at the time suggested that President Trump would be more moderate that Candidate Trump had been, so perhaps the shift in views among Democrats reflected an effort to reduce discomfort about the incoming administration. These changes in positive feelings toward the Republican Party in turn shifted views about climate change. At least since the Reagan Administration, the Republican Party has tended to oppose environmental regulation, and climate change denial has become almost universal among Republican leadership (Dietz 2020; Fisher et al. 2018). Increased positive feeling toward a party where climate denial is commonplace led to reduced concern with climate change. The impact was stronger for Republicans than for Democrats, so the effect of Trump's election in the short run was to widen the ideological split on climate change. As the authors note, their data is capturing the effect of the election itself, not the actions of the Trump administration.

Zawadzki et al. were not able to re-interview the same respondents, but they have data from four time points: the day before the election, 20 days after Trump took office and began to issue Executive Orders, 100 days into his presidency (which is often seen as a benchmark in a new administration), and 10 days after Trump began the process of withdrawing the USA from the Paris Climate Agreement, the 151st day of his presidency. So while Hahnel et al. are capturing the impact of the election per se, Zawadzki et al. provide insights into the impact of Trump's early actions as President and the reaction to them, such as the March for Science (April 22, 2017) and the People's Climate Mobilization (April 29, 2017), both of which occurred just before Trump's 100th day in office.

They find that once Trump was in office and his views on climate, the environment, and government regulation were instantiated in policy actions, the effect was to some degree the opposite of what Hahnel et al. found when looking immediately after the election. Trump 
supporters still became less likely to accept the reality of climate change but non-supporters became more likely to believe that climate change is real, anthropogenic, and a serious threat. The two papers use somewhat different measures of climate views, but I believe the results are consistent. The immediate effects of the national election were better feelings toward the victors and more resonance with their views. But once policies emerged that clarify what the new administration would do, supporters became less accepting of the scientific consensus while opponents became more accepting. Both of these effects tend to increase polarization. Similar effects seem to follow from gubernatorial elections (Meyer 2019).

Once Trump announced that the USA was withdrawing from the Paris Treaty, climate beliefs among his opponents became stronger. Perhaps surprisingly, denial of the scientific consensus declined among his supporters, who moved back to climate beliefs roughly equivalent to their pre-election views. The move among opponents might be seen as a defensive posture. Given a President who seems hostile to environmental policy, opponents strengthen their pro-environmental position. A similar pattern has been observed around the passage of US federal environmental law, where environmental legislation is most likely to be passed when a Democratic Congress faces a Republican president - the legislative action seems intended to counter possible actions by the president (Steele 2020). Hahnel et al. suggest that Trump's supporters may have shifted views because Trump's speech on the Paris Treaty acknowledges the reality of climate change. Alternatively, withdrawal from the Paris accords and related reneging on commitments to reduce greenhouse gas emissions removed the policy threat that comes with climate mitigation. That in turn may have reduced the need of mitigation policy opponents to reject the scientific consensus.

\subsection{Processes of change}

Both papers use the 2016 Presidential election as a natural experiment to examine the processes that can shift public views on climate change. They not only show the election's effect on climate denial but also explore the mechanisms by which that happened. Hahnel et al. analysis is consistent with a process that has been extensively examined in policy networks - we tend to shift our views to make them more in alignment with those we view positively. In policy systems, actors tend to affiliate with those with similar views, avoid those with opposing views, and accept information mostly from those who are like-minded and that are resonant with our prior views. These effects can be very strong and make it difficult to address complex issues such as climate change (Henry and Vollan 2014; Henry et al. 2020).

Zawadzki et al. examine the processes that may lead to, or block, public action on climate change. Much of the literature on pro-environmental behavior demonstrates the importance of what Zawadzki et al. refer to as "moral sentiments," often called altruism in other literatures. People take action because they are concerned with the well-being of other humans and other species, and because they feel a personal obligation to act on problems like climate change (Steg 2016). Their analysis shows that believing either that climate change is anthropogenic, and/or that it is serious, increases the moral sentiment that one should act. That in turn leads to a greater likelihood of being willing to reduce energy consumption and support climate policy. Trump's presidency tended to reduce these climate beliefs among his supporters while increasing them among his opponents. Those changes in beliefs, acting through changes in moral sentiments, led to increased willingness to take action among Trump opponents and decreased willingness among supporters. 


\subsection{What next?}

How can we encourage social change that leads to a just and sustainable global society? How can the gap between scientific assessment of climate risks and climate action be closed? Social change comes about through the interplay of actions by the public, by political elites, and by activists who work to influence both elites and the public. The last century has seen massive social and policy change around the environment and civil rights, for example (Dietz 2020; Silver 2015). Understanding how these processes unfold, particularly in the face of urgent sustainability challenges, must be a high priority for social science research. These two papers demonstrate the potential of linking the analysis of large-scale events, such as elections, to individual-level processes.

Unfortunately, while conceptual frameworks and research methodologies exist to undertake that challenge, resources to support such efforts are sadly lacking. The environmental social sciences receive very modest funding relative to their potential contribution (Overland and Sovacool 2020). One result is that the kind of long-term, consistent community data sets needed to untangle causal effects and to link the micro and the macro are seldom available. One can imagine the state of climate science if funding over recent decades had precluded the production of high-quality time series data and allowed only episodic observations scattered unsystematically across time and space. Yet, that is exactly the situation faced by the social sciences.

Nonetheless, a great deal of progress is being made. In particular, a rapidly evolving literature helps us to understand the individual-level processes that lead to agreement with scientific consensus. The literature also makes clear what leads to action by individuals in their roles as both consumers and citizens. Our understanding is increasingly integrated across multiple disciplines and perspectives, although most research is still grounded in Western, educated, industrial, rich democracies (Nielsen et al. 2020; Steg 2016; Steg et al. 2018).

Hahnel et al. and Zawadzki et al. take that literature in an important new direction. Their analyses are solidly grounded in, and make contributions to, our understanding of the social psychological processes that shape climate beliefs and willingness to take action on climate change. But they go a step further in linking those individual-level models to large-scale political events, in this case the election of a Republican president aligned with climate denial and opposed to climate policy. Understanding how these large-scale events shape individual views, including the mechanisms involved, is critically important but the neccessary analyses are rarely done, in part because of the lack of time series data noted above. We need more analyses of this sort, as well as analyses that trace causal influence in the opposite direction, from citizens and consumers to large-scale social change. The processes by which changes in individual beliefs, norms, and actions influence businesses and government are complex and fraught with sharp power differentials between the average citizen or consumer and the powerful individuals and organizations that shape policy and the economy (Dietz and Whitley 2018). But individuals do have an impact, and we need a better understanding of how it unfolds. Work on this issue may be most advanced around how consumer choices have impacts not only on direct consumption of energy in the household but also impacts on the supply chain (Gilligan and Vandenbergh 2020; Stern and Dietz 2020). Social movement scholars have examined how mobilization can influence policy (Fisher et al. 2019). But more work is needed to understand how social movement support by individuals influences largerscale social change to parallel needed work on how large-scale changes influence individuals. 
Of course, readers of Climactic Change will ask how these results, and the literature on which they build, can help close the gap between current actions on climate change and what is needed to reduce risks to an acceptable level. Certainly, we are learning how to communicate science more effectively (Moser 2016; U.S. National Academies of Science 2016). But, since decisions always involve both facts and values, even if the public and policy makers agreed with the scientific consensus on the magnitude, impacts, and risks of climate change, there is still considerable room for debate based on value differences and inequities entrained in climate mitigation and adaptation.

Nearly a century ago, John Dewey noted the difficulty of resolving problems that are grounded in science and that involve value conflicts (Dewey 1923). He called for linking scientific assessment with deliberation by interested and affected parties. The US National Academies of Science has argued repeatedly that such linked analysis and deliberation can help build trust in science and mutual understanding even in the face of value differences (U.S. National Research Council 2010; U.S. National Research Council 2005; U.S. National Research Council 1996). We know a great deal about how to structure successful analytic deliberative processes at the local and regional level (Bidwell 2016; Stern 2013). Climate change challenges us to develop processes that can work at the national and global levels (Bächtiger et al. 2018). As we try to move in that direction, work such as that of Hahnel et al. and Zawadzki et al. is crucially important in providing the scientific underpinning that links large-scale processes and events to change in the views and actions of individuals.

\section{References}

Algara C, Hale I (2019) The distorting effects of racial animus on proximity voting in the 2016 elections. Elect Stud 58:58-69

Bächtiger A, Dryzek JS, Mansbridge J, Warren ME (eds) (2018) Oxford handbook of deliberative democracy. Oxford University Press, Oxford

Ballew MT et al (2019) Climate change in the American mind: data, tools, and trends. Environ Sci Policy Sustain Dev 61:4-18

Bidwell D (2016) Thinking through participation in renewable energy decisions. Nature Energy 1:16051

Bolsen T, Palm R (2019) Motivated reasoning and political decision making. In: Thompson WR (ed) Oxford research encyclopedia of politics. Oxford University Press, Oxford. https://doi.org/10.1093 /acrefore/9780190228637.013.923

Bomberg E (2017) Environmental politics in the Trump era: an early assessment. Environ Polit 26(5):956-963

Cialdini RB (2007 [1984]) Influence: the psychology of persuasion. Revised Edition edn. HarperCollins, New York

Dewey J (1923) The public and its problems. Henry Holt, New York

Dietz T (2013) Bringing values and deliberation to science communication. Proc Natl Acad Sci 110:1408114087

Dietz T (2020) Earth day: fifty years of continuity and change in environmentalism. One Earth. https://doi. org/10.1016/j.oneear.2020.04.003

Dietz T, Whitley CT (2018) Inequality, decisions, and altruism. Soc Dev 4:282-303

Druckman JN, McGrath MC (2019) The evidence for motivated reasoning in climate change preference formation. Nature Clim Chang 9:111-119

Elliott KC (2017) A tapestry of values: an introduction to values in science. Oxford University Press, New York

Fisher DR, Robertson AMG, Waggle JM, Dewey AM, Dubin AH, Yagatich W (2018) Polarizing climate politics in America. In: Alagan R, Aladuwaka S (eds) Environment politics, and society, vol 25. Emerald Publishing Limited, Bingley, p 1-23

Fisher DR et al (2019) The science of contemporary street protest: new efforts in the United States. Science Advances 5:eaaw5461 
Gilligan JM, Vandenbergh MP (2020) Private climate governance. Energy Res Soc Sci 60:101400. https://doi. org/10.1016/j.erss.2019.101400

Givens JE, Hazboun SO, Briscoe MD, Krannich RS (2020) Climate change views, energy policy support, and personal action in the Intermountain West: the anti-reflexivity effect. Soc Nat Resour 1-23. https://oi. org/10.1080/08941920.2020.1769782

Hahnel UJJ, Mumethaler C, Brosch T (2020) Emotional foundations of the public climate change divide, Climatic Change https://doi.org/10.1007/s10584-019-02552-0

Henrich J (2015) The secret of our success: how culture is driving human evolution, domesticating our species, and making us smarter. Princeton University Press, Princeton, NJ

Henry A, Vollan B (2014) Networks and the challenge of sustainable development. Ann Rev Environ Resour 39: 583-610

Henry AD, Dietz T, Sweeney R (2020) Coevolution of networks and beliefs in U.S. environmental risk policy. Policy Studies Journal In press

Hooghe M, Dassonneville R (2018) Explaining the Trump vote: the effect of racist resentment and antiimmigrant sentiments. PS Political Sci Polit 51:528-534

Hornsey MJ, Harris EA, Fielding KS (2018) Relationships among conspiratorial beliefs, conservatism and climate scepticism across nations. Nat Clim Chang 8:614-620. https://doi.org/10.1038/s41558-018-0157-2

Jasny L, Dewey AM, Robertson AG, Yagatich W, Dubin AH, Waggle JM, Fisher DR (2018) Shifting echo chambers in US climate policy networks. PloS One 13(9). https://doi.org/10.1371/journal.pone.0203463

Johnson EW, Schwadel P (2019) Political polarization and long-term change in public support for environmental spending. Soc Forces 98:915-941

Kahneman D (2011) Thinking fast and slow. Farrar, Straus \& Giroux, New York

McCright AM (2016) Anti-reflexivity and climate change skepticism in the US general public. Hum Ecol Rev 22:77-108

McCright AM, Dunlap RE (2010) Anti-reflexivity: the American Conservative Movement's success in undermining climate science and policy theory. Cult Soc 27:100-133

McCright AM, Marquart-Pyatt ST, Shwom RL, Brechin SR, Allen S (2016) Ideology, capitalism, and climate: explaining public views about climate change in the United States. Energy Res Soc Sci 21:180-189. https://doi.org/10.1016/j.erss.2016.08.003

McLaughlin P (2012) Climate change, adaptation, and vulnerability: reconceptualizing societal-environment interaction within a socially constructed adaptive landscape. Organ Environ 24:269-291

McLaughlin P, Dietz T (2008) Structure, agency and environment: toward an integrated perspective on vulnerability. Glob Environ Chang 18:99-111

Meyer AG (2019) Elite influence on climate change skepticism: evidence from close gubernatorial elections. J Assoc Environ Resour Economists 6:783-822

Michaels D (2020) The triumph of doubt: dark money and the science of deception. Oxford University Press, Oxford

Moser SC (2016) Reflections on climate change communication research and practice in the second decade of the 21 st century: what more is there to say? Wiley Interdiscip Rev Clim Chang 7:345-369

Nielsen KS, Clayton S, Stern PC, Dietz T, Capstick S, Whitmarsh L (2020) How psychology can help limit climate change. Am Psychol. https://doi.org/10.1037/amp0000624

Overland I, Sovacool BK (2020) The misallocation of climate research funding. Energy Res Soc Sci 62:101349. https://doi.org/10.1016/j.erss.2019.101349

Rosenbaum WA (2020) Environmental politics and policy, 11th edn. CQ press, Thousand Oaks

Setzler M, Yanus AB (2018) Why did women vote for Donald Trump? PS Political Sci Polit 51:523-527

Silver N (2015) Change doesn't usually come this fast FiveThirtyEight.com

Steele C (2020) An analysis of U.S. federal environmental legislation in the nineteenth, twentieth and beginning twenty-first centuries, with emphasis on presidential party and political majorities in congress. J Legis Stud: 1-19. https://doi.org/10.1080/13572334.2020.1726634

Steg L (2016) Values, norms, and intrinsic motivation to act pro-environmentally. Ann Rev Environ Resour 41: 277-292

Steg L, Shwom R, Dietz T (2018) What drives energy consumers?: engaging people in a sustainable energy transition. IEEE Power Energy Mag 16:20-28

Stern PC (2013) Design principles for governing risks from emerging technologies. In: Dietz T, Jorgenson AK (eds) Structural human ecology: new essays in risk. Energy and Sustainability. Washington State University Press, Pullman, pp 91-118

Stern PC, Dietz T (2020) A broader social science research agenda on sustainability: nongovernmental influences on climate footprints. Energy Res Soc Sci 60:101401. https://doi.org/10.1016/j.erss.2019.101401

U. S. National Research Council (2005) Public participation in environmental assessment and decision making. National Academies Press, Washington 
U.S. National Research Council (2010) Advancing the Science of Climate Change. National Academies Press, Washington

U.S. National Academies of Science (2016) Communicating science effectively: a research agenda. National Academies Press, Washington

U.S. National Research Council (1996) Understanding risk: informing decisions in a democratic society. National Academies Press, Washington

Wright JD, Esses VM (2019) It's security, stupid! Voters' perceptions of immigrants as a security risk predicted support for Donald Trump in the 2016 US presidential election. J Appl Soc Psychol 49:36-49

Zawadzki SJ, Bouman T, Steg L, Bojarskich V, Druen PB (2020) Translating climate beliefs into action in a changing political landscape. Climatic Change. https://doi.org/10.1007/s10584-020-02739-w

Publisher's note Springer Nature remains neutral with regard to jurisdictional claims in published maps and institutional affiliations. 